\title{
Design Criteria of Under-Deck Cable-Stayed Composite Bridges for Short and Medium Spans
}

\author{
Fernando Madrazo-Aguirre, Research Student; Ana M. Ruiz-Teran, Dr., Lecturer in Bridge Engineering; M. Ahmer Wadee, Dr., \\ Reader in Nonlinear Mechanics; Imperial College London - Civil and Environmental Eng., London, UK. \\ Contact: fmadrazoaguirre@gmail.com
}

DOI: $10.2749 / 101686615 X 14210663188574$

\begin{abstract}
Under-deck cable-stayed bridges are innovative bridge schemes that can lead to lightweight and highly efficient construction. However, the design of slender bridges may be governed by the vibrations under traffic live loads. After a historical review of bridges with under-deck cable-staying systems and the consequent research, the dynamic response of medium- and short-span bridges is analysed. Eccentric traffic loads are shown to increase accelerations considerably, and the second vertical mode is found to be the main contributor to the response. A parametric study shows the strong influence of resonance effects in the maximum accelerations registered on the deck. In addition, under-deck cable-staying systems are found to be more appropriate for medium-span than for short-span bridges from the dynamic viewpoint. Moreover, for medium spans, much more slender decks can be achieved compared with conventional bridges without cable-staying systems. Finally, some design criteria are provided that may be useful for structural designers.
\end{abstract}

Keywords: bridges; cable-supported; under-deck cable-stayed bridges; innovative structural systems; dynamic; moving loads.

\section{Introduction}

\section{Under-Deck Cable-Stayed Bridges: Examples, Historical Precedents and Research}

Under-deck cable-stayed bridges (UDCSBs) define an innovative bridge typology in which the stay cables follow non-conventional layouts in comparison with those of conventional cable-stayed bridges, ${ }^{1}$ the stays being located underneath the deck. ${ }^{2}$ The pre-tensioned stays, which are selfanchored to the deck, provide elastic supports to the deck by means of the struts, reducing, in turn, the bending moments acting on the bridge.

In the following section, a historical review of UDCSBs with different deck typologies (e.g. prestressed concrete, steel-concrete composite, steel) is completed. Even though the socalled UDCSBs have been built since the 1970s, a very similar structural

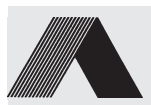

Peer-reviewed by international experts and accepted for publication by SEI Editorial Board

Paper received: September 16, 2014

Paper accepted: January 16, 2015 configuration, the under-deck suspension bridge, dates back to the nineteenth century. In these bridges, in which the cables are not actively pretensioned, the suspension cables are usually anchored to the abutments, whereas the stay cables are prestressed and self-anchored to the deck in UDCSBs. However, when cables are self-anchored and very slender decks are employed, the behaviour of underdeck suspension bridges is very similar to that of UDCSBs. Some examples of suspension bridges with underdeck cables include the Almond River Bridge in Scotland by R. Stevenson, built in $1821^{3}$; the Bergues Bridge in France, built in $1834^{3}$; the Bel-Air Bridge at la Coulouvreniere, built in $1837^{3}$; the Potomac River crossing in Maryland, built in 1856 by Wendel Bollman ${ }^{4}$; the proposal for a viaduct for Blackwell's Island Bridge in 1869 by Thomas C. Clarke ${ }^{5}$; the Oak Ridge viaduct proposed by Charles Macdonald ${ }^{6}$. a railroad viaduct built at Biesenbach, Germany $^{7}$; the Karstelenbach Bridge in Amsteg, Switzerland, ${ }^{7}$ that was built in 1882 and stiffened in 1908; and the Varrugas Bridge in Peru. ${ }^{8}$ In that century, Fink trusses also became popular for the purpose of resisting the heavy loads in railway bridges. ${ }^{9}$
The prestressing technique, which was introduced in the 20th century, allowed for the prestressing of the cables to control the behaviour of cable-supported bridges. As a result, under-deck suspension bridges were constructed by employing prestressed concrete elements, in which the cables were embedded in concrete, as tensile elements, such as the Rio Colorado Bridge in Costa Rica in 1972 designed by T.Y. Lin, ${ }^{10}$ and the Breno bridge, the bridge over Capriasca River, and the bridge over Tessina River designed by A. Muttoni. ${ }^{11}$ Fritz Leonhardt designed the first UDCSB with bare stay cables: the Weitingen viaduct over the Neckar River in Germany, which was completed in $1978 .{ }^{12}$ In this viaduct, the initially proposed lateral piers were replaced by under-deck cable-staying systems that introduced vertical forces into the deck. Since then, several UDCSBs have been designed and built, most of which are discussed in Ref. [13]. Moreover, this bridge typology has been adopted by many well-known engineers worldwide, such as Jörg Schlaich in the initial proposal for the Kirchheim overpass, ${ }^{14}$ Michel Virlogeux in the Truc de la Fare overpass, ${ }^{15}$ Javier Manterola in the Osormort viaduct, ${ }^{16}$ Leslie E. Robertson in the Miho Museum footbridge ${ }^{17}$ and Jean Marie Cremer in the Jumet footbridge. ${ }^{18}$ The construction in 1991 of the first combined cable-stayed bridge (CCSB) - the Obere Argen viaduct-designed by Jörg Schlaich is also remarkable. ${ }^{19}$ In CCSBs, the stays are located both over and under the deck, as a result of the combination of conventional and under-deck cable-stayed bridges.

Since the publication of Ref. [13] in 2010, new UDCSBs have been built, and some of the bridges identified by the authors are included in Table 1. In addition, under-deck cable-stayed systems have been used widely in many other applications, such as stiffening beams, ${ }^{20}$ roof structures, ${ }^{21}$ pipeline crossings $^{22}$ and self-launching gantries. $^{23}$ 


\begin{tabular}{|l|c|c|}
\hline Bridge & Country & Reference \\
\hline Footbridge over Mur River in Graz & Austria & {$[24]$} \\
\hline Thuin bridge & Belgium & {$[25]$} \\
\hline Ganmon bridge & Japan & {$[26]$} \\
\hline Seiun highway bridge & Japan & {$[26]$} \\
\hline Seishun bridge & Japan & {$[26]$} \\
\hline San Miguelito footbridge (Fig. 1a) & Mexico & {$[27]$} \\
\hline Okuno bridge (Fig. 1b) & Japan & {$[28]$} \\
\hline Boukei bridge & Japan & {$[29]$} \\
\hline Compiègne bridge & France & {$[30]$} \\
\hline Private glass footbridge near Nice & France & {$[31]$} \\
\hline Proposal for Johnson Creek bridge & USA & {$[8]$} \\
\hline Awa Shirasagi Ohashi bridge (CCSB) & Japan & {$[32]$} \\
\hline
\end{tabular}

Table 1: Recently designed bridges with under-deck and combined cable-staying systems

Regarding the research carried out on bridges and beams with underdeck cable-staying systems, a thorough review of the literature was conducted in Ref. [2], where the research works covered were laboratory tests on beams, with analyses and parametric studies of the structural response. An in-depth analysis of the parameters governing the response of both UDCSBs and CCSBs was performed in Ref. [33], and efficient configurations for decks with post-tensioned concrete slabs were proposed in Refs. $[34,35]$ by employing under-deck and combined cable-staying systems. Recently, in Ref. [36], further analyses were performed on UDCSBs employing a doublelevel structural system, which approximates to Fink truss configurations. The response of UDCSBs under accidental events has also been studied. ${ }^{37,38}$ Finally, different configurations for CCSBs have been analysed in Ref. [39].

\section{Structural Behaviour}

The response of UDCSBs under dead load is controlled by the dead load compensation level $\rho$ : the portion of the cable-staying system. ${ }^{33}$ The compensation $\rho$ is calculated as the ratio between the vertical permanent load introduced by the struts into the deck and the vertical reaction found on a continuous deck with rigid supports in the strut-deck connection sections (see Fig. 2a). In UDCSBs with concrete decks, compensation levels of $100 \%$ are appropriate to adopt ${ }^{34}$ while steel and composite decks may accept higher values because of the lack of, or negligible (for this purpose), creep effects, respectively. The span subdivision concept can be derived from the compensation $\rho$. In a two-strut UDCSB, if a compensation of $100 \%$ of the dead load is achieved, the effective span of the bridge is reduced to $1 / 3$ and, hence, bending moments under dead load to $1 / 9$, in effect, the effective span is divided into three subspans.

The response under live load is governed by the efficiency of the cablestaying system $\xi$, which can be defined as the ratio between the moment the dead load that is compensated by resisted by the cable-staying system (i.e. the couple formed by the tension in the cables and the compression on the deck) and the bending moment that would exist on the deck without the cable-staying system $\left(\mathrm{qL}^{2} / 8\right),{ }^{33}$ (see Fig. $2 b$ ). The efficiency $\xi$ depends on the relative flexural stiffness of the deck to the cable-staying system, as well as on the support conditions and types of loads applied on the bridge. The flexural stiffness of the cablestaying system is proportional to the cross-sectional area and eccentricity of the stay cables. The higher the relative flexural stiffness of the cablestaying system, the higher its efficiency $\xi$, and consequently, the lower the bending moments because of the live load in the deck. In medium-span UDCSBs with post-tensioned concrete decks, efficiency values of 0.90 can be reached, ${ }^{34}$ that is the cable-staying system resists $90 \%$ of the live load, while the other $10 \%$ is resisted by means of the bending of the deck. Owing to the much lower efficiency of under-deck cable-staying systems in continuous bridges, UDCSBs are appropriate for simply supported schemes. ${ }^{35}$

UDCSBs with prestressed concrete decks present several advantages compared with conventional bridges without stay cables for medium spans ${ }^{34}$ : (a) a higher structural efficiency by reducing the flexural demand on the deck and enhancing the axial response; (b) a significantly higher deck slenderness; (c) reduction of the amount of materials needed, allowing for a more sustainable construction as a consequence; (d) multiple construction possibilities; and (e) arguably, strong aesthetic characteristics. In fact, several international design prizes have been awarded to examples of this bridge typology. In (a)

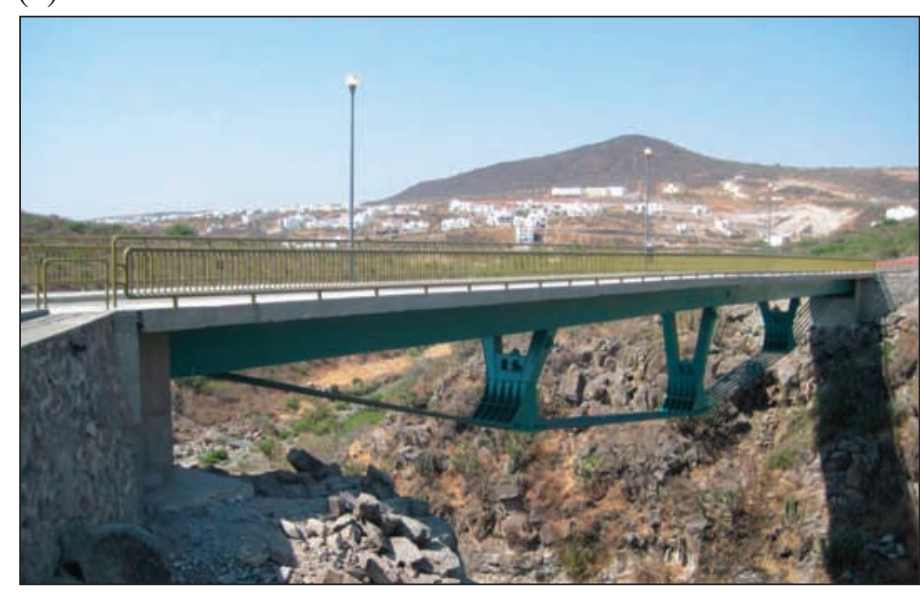

(b)

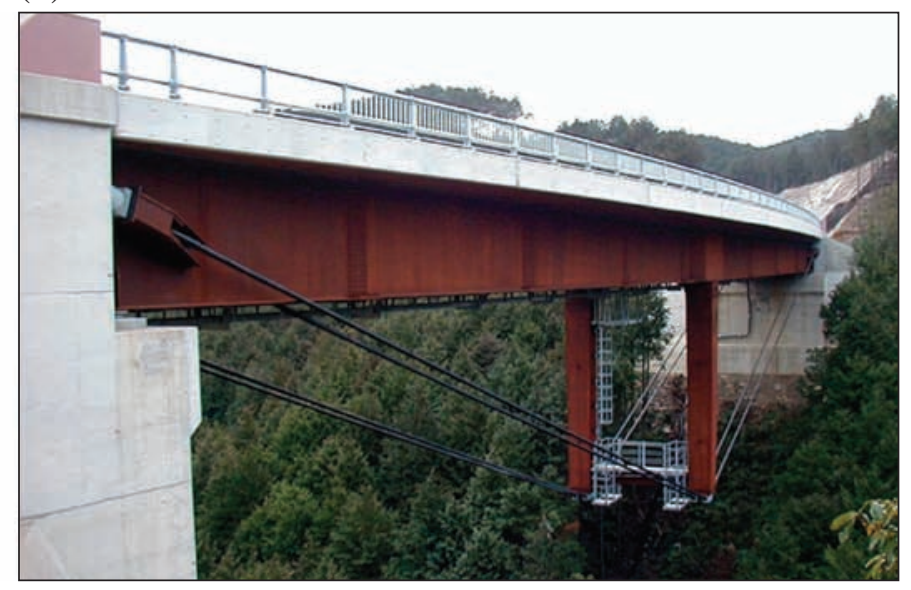

Fig. 1: Two recent examples of under-deck cable-stayed bridges with composite decks: (a) San Miguelito creek footbridge in Querétaro (Mexico) and (b) Okuno bridge in Japan 
(a)
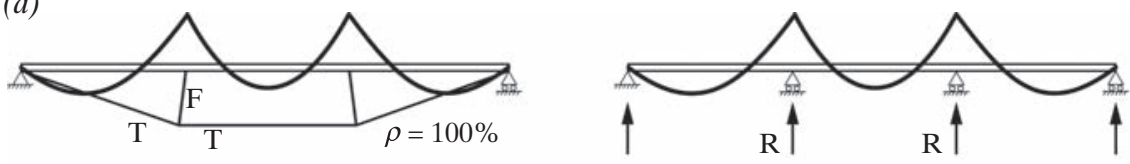

(b)

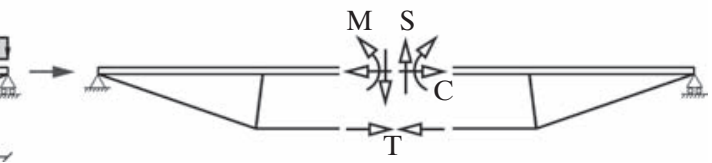

Fig. 2: Static response of UDCSBs under (a) dead load, in which a compensation level $\rho$ of $100 \%$ produces a deviation force F in the stay cables (which are under a tension force $T$ ), whose vertical component is equal to the vertical reaction $R$ found on a continuous beam over rigid supports (bending moment diagrams are plotted); the horizontal component of this force $F$ introduces an additional axial force into the deck; (b) live load, in which the load is resisted by means of the flexural response within the deck (i.e. bending moment M and shear force $S$ ) and the axial response of the cable-staying system (i.e. a couple formed by the tension force within the stays $T$ and the compression force within the deck $C$ )

medium-span UDCSBs with prestressed concrete decks, depths of $1 / 80$ of the total span can be achieved, reducing the self-weight to $30 \%$ as a consequence. Hence, UDCSBs are an entirely appropriate solution when there is sufficient clearance to fit the stay cables.

\section{Steel-Concrete Composite Decks}

Steel-concrete composite decks seem prima facie to be appropriate for UDCSBs, because the deck flexibility enhances the axial response of the cable-staying system. Furthermore, apart from being lightweight solutions with high durability (pre-compressed concrete slab, careful execution of details, facility for inspections and intervention), composite decks allow for a high proportion of prefabrication with its obvious advantages: quality, precision, safety and construction speed. ${ }^{40,41}$

However, when slender decks are designed, vibrations caused by live load may begin to be perceptible by the bridge users, and the serviceability limit states (SLS) may become critical. In fact, in medium-span UDCSBs with post-tensioned concrete decks, the SLS of vibrations under traffic live load determines the maximum slenderness of the deck. ${ }^{34,35}$ Furthermore, lower self-weight to live load ratios ${ }^{42}$ of composite decks suggest that the comfort criterion could be one of the governing limit states. In this study, the characterization of the dynamic behaviour of road UDCSBs under the action of traffic moving loads was performed. This is a necessary step to gain a sound understanding of the dynamic response of UDCSBs with composite decks, before assessing the vibrations by employing moving vehicles (i.e. by introducing into the model the vehicle-structure interaction, pavement roughness, etc.). ${ }^{43}$
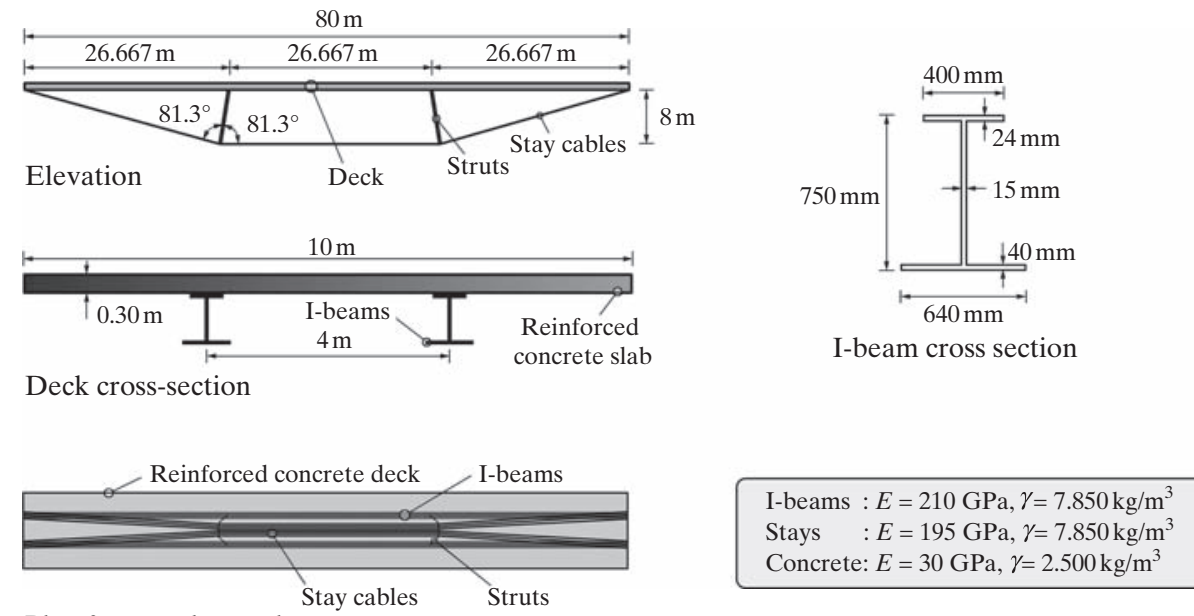

Plan from underneath

Stay cables

Fig. 3: Geometry and mechanical properties of the $80 \mathrm{~m}$ UDCSB considered in this work

\section{Structural Model}

Single-span simply supported road bridges were studied in this work. Initially, an $80 \mathrm{~m}$ span was analysed, which is characteristic of the mediumspan range and can be compared with previous studies. ${ }^{34}$ Subsequently, the influence of the span length was also investigated by means of a bridge with a shorter span of $40 \mathrm{~m}$. Owing to the efficient structural behaviour, UDCSBs with two struts and a stay eccentricity of $10 \%$ of the total span were employed. With this configuration, the deck was effectively divided into three equal subspans (Fig. 3). A composite deck formed by two longitudinal steel I-beams and a reinforced concrete deck was considered. The cable-staying system was formed by six stays, which were divided into two families. Both families were located next to each other in the central subspan, and forked at lateral subspans, to provide a higher torsional stiffness to the deck ${ }^{44}$ as well as to facilitate the anchorage to the deck. As a consequence, each family was anchored into one I-beam at the support sections, the resultant of the axial forces in the stays being applied at the level of the centroid of the full composite section to avoid the introduction of moments in these sections. Each stay comprised 31 strands of 150 $\mathrm{mm}^{2}$ each. Struts bisected the angle of the polygonal layout of the stay cables and were pinned to the deck. Hence, the struts were subjected only to axial loads and the introduction of concentrated bending moments into the deck was avoided. Furthermore, each of the two struts was formed by two compression members that allowed for the support of both I-beams. Design calculations by considering only static analyses led to a deck depth to span ratio of $1 / 76.45$

A three-dimensional linear elastic finite element (FE) model was employed to simulate the dynamic response of the UDCSB. A well-established commercial FE package ${ }^{46}$ was used for this purpose. The load value, which represented a fully loaded truck often employed in loading tests, was considered to be $400 \mathrm{kN},{ }^{47}$ which is consistent with current traffic conditions on European roads. ${ }^{48}$ The moving load 
$F$ was represented as a summation of multiple surface loads that changed in time with a piecewise linear function:

$F(t)=\sum_{i=1}^{n} \delta_{i}(t, \Delta t) q_{i}$

where $n, \delta_{1}, \Delta t$ and $q_{\mathrm{i}}$ were the number of surfaces considered (equal to the span of the bridge in metres in this work), the time-dependent piecewise linear function associated with each surface (Fig. 4), the time that the load needed to move from one surface to the one adjacent, and the surface load, respectively. Hence, the moving speed of the load could be varied by adjusting the value of $\Delta t$. Moreover, the total load applied on the deck was constant in time while the load was over the deck, which modelled the effect of a moving load properly.

The modal superposition method was employed to assess the dynamic response of the bridge under moving loads. A parametric analysis suggested that 10 modes could provide satisfactory results, given that modes with a high frequency were not of interest in this work. Apart from the self-weight of the structural elements, an additional load of $43.11 \mathrm{kN} / \mathrm{m}$ was considered that accounted for the weight of non-structural elements such as the pavement and the parapets. The structural damping ratio was assumed to be equal to $1 \%$. The effect of the stiffness modification of pre-tensioned elements was also considered. This effect decreased (less than 5\%) the flexural mode frequencies slightly because the deck was subjected to compression loads.

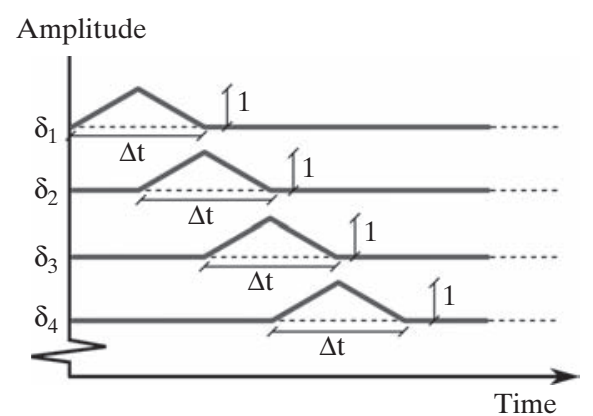

Fig. 4: Time-dependent piecewise linear function $\delta_{i}$ associated with each surface load
Initially, when measuring accelerations, maximum accelerations were taken into account, as the peak values of the accelerograms obtained at different points of the deck. Other acceleration values different from the peaks were also considered. The FE model was validated with previous studies, ${ }^{34}$ leading to very similar acceleration values and distributions along the deck.

\section{Dynamic Response of Medium Spans}

\section{Modal Analysis}

Initially, the vibration modes and the corresponding frequencies were obtained by solving the linear eigenvalue problem. For simplicity, the modal shape of each mode was denoted by a letter ("V" for vertical, "T" for torsional and "L" for lateral) followed by a number that referred to the number of half-waves found on that particular mode (Fig. 5 and Table 2).

For the particular bridge configuration studied herein, the natural mode (i.e. the lowest frequency mode) was observed to be V2. The mode V1 implies principally the axial deformations of both the stay cables and the deck, and because of the large axial stiffness of the stays in comparison with the flexural stiffness of the deck, the second flexural mode V2 becomes the natural mode. A similar effect is also observed in some stress ribbon structures $^{8}$ and arch bridges. Since both vertical and torsional mode frequencies were in close proximity, torsional modes are predicted to participate in the dynamic response.

\section{Load Eccentricity}

Accelerations were measured for two load cases: concentric and eccentric loads. While concentric load cases, which are loads that are applied with no eccentricity to the cross-section of the deck, do not excite torsional modes, eccentric loads certainly do so, and hence accelerations may be higher. For the concentric load case, accelerations were measured in the centre of the cross-section of the deck since the maximum differences between the accelerations at different points of the cross-section were less than 5\%. However, for the eccentric load case, in which the load was applied with a $2.0 \mathrm{~m}$ eccentricity, the centre and both edges were considered since the maximum accelerations were usually registered at the edge of the cross-section where the load was applied.

Figure $6 a$ shows the maximum vertical acceleration envelope for the previously mentioned two load cases, in which the load travels at a speed of $80 \mathrm{~km} / \mathrm{h}$ along the deck. The first observation is the lack of symmetry of the acceleration envelope. This effect is due to the different time history records that are registered at any two symmetric points. Both envelopes show two relative maximum accelerations, none of them being located at mid-span, which would be expected in a simply supported beam. Maximum accelerations are located at lateral subspans in both load cases. While for the concentric load case, the maximum acceleration $\left(0.62 \mathrm{~m} / \mathrm{s}^{2}\right)$ is registered in the first subspan (in relation to the movement of the load), for the eccentric load case, the maximum acceleration $\left(0.89 \mathrm{~m} / \mathrm{s}^{2}\right)$ is found in the third subspan. As a consequence, the eccentric load produces a maximum acceleration that is $43.5 \%$ higher.

\section{Parametric Analysis}

In this section, a parametric analysis is performed, in which the speed of the load and the depth of the I-beams $(d)$ are varied. Load speeds vary from 60 to $80 \mathrm{~km} / \mathrm{h}$ in increments of $5 \mathrm{~km} / \mathrm{h}$, while $d$ values vary from 675 to 1350 $\mathrm{mm}$ in increments of $75 \mathrm{~mm}$.

Modal frequencies are modified when the $d$ parameter is varied (see Fig. 6b). Since the stiffness of the system is raised by increasing $d$, the frequencies also increase. However, the frequencies of modes V2 and V3 increase at a higher rate than frequencies of other modes such as V1 and T1, and hence $d$ does not affect all the modes equally. As a result, while the natural mode is V2 for the lowest values of $d$, if the deck is sufficiently stiff, V1 becomes the natural mode.

Figure $7 a$ shows the maximum acceleration registered at any point of the deck for each speed- $d$ combination for
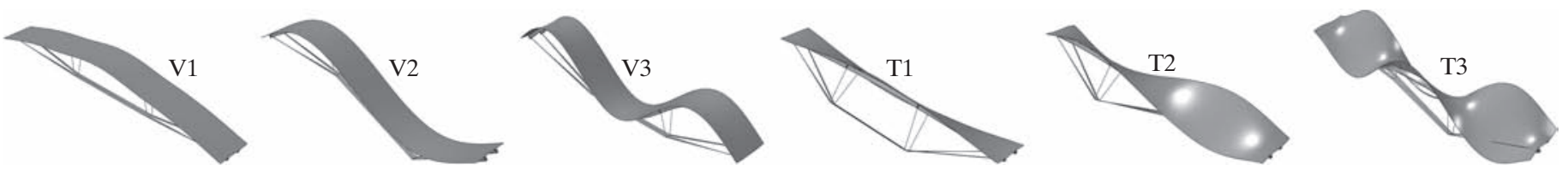

Fig. 5: First three vertical $(V)$ and torsional $(T)$ modal shapes 


\begin{tabular}{|c|c|c|c|c|c|}
\hline Mode & Frequency $(\mathbf{H z})$ & Modal shape & Mode & Frequency (Hz) & Modal shape \\
\hline 1 & 0.794 & $\mathrm{~V} 2$ & 6 & 2.048 & L1+T3 \\
\hline 2 & 0.986 & $\mathrm{~V} 1$ & 7 & 2.552 & $\mathrm{~T} 3$ \\
\hline 3 & 1.040 & $\mathrm{~T} 1$ & 8 & 3.055 & V4 \\
\hline 4 & 1.731 & $\mathrm{~T} 2$ & 9 & 3.560 & $\mathrm{~T} 4$ \\
\hline 5 & 1.756 & $\mathrm{~V} 3$ & 10 & 4.617 & V5 \\
\hline
\end{tabular}

Table 2: First 10 vibration modes and the corresponding frequencies and modal shapes
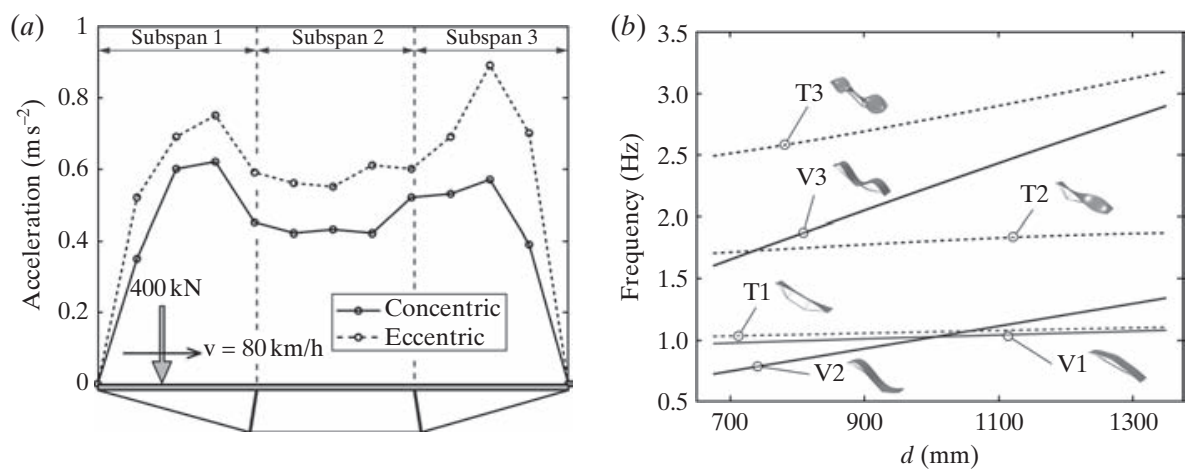

Fig. 6: (a) Maximum acceleration envelopes along the deck for the concentric and eccentric load cases and a load speed of $80 \mathrm{~km} / \mathrm{h}$ for $d=750 \mathrm{~mm}$. (b) Variation of the modal frequencies with the depth of I-beams $d$
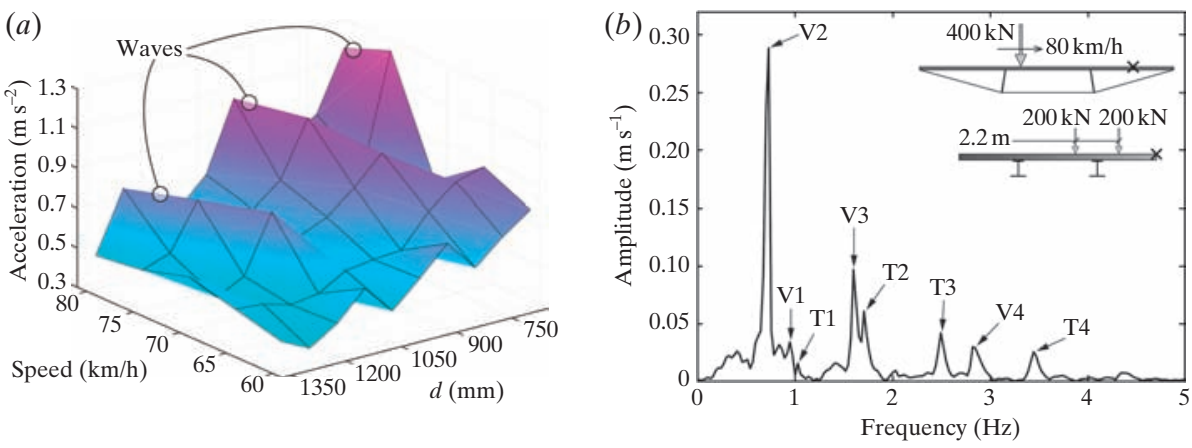

Fig. 7: (a) Maximum acceleration envelope for the eccentric load case. (b) Frequency domain response of the accelerations at the edge of the middle section of the last subspan for a load speed of $80 \mathrm{~km} / \mathrm{h}$ and $d=675 \mathrm{~mm}$

the eccentric load case. These maximum accelerations define an envelope surface that is not planar and presents some clear waves, higher accelerations being located in the "peaks" of these waves, and lower accelerations in the "valleys". Therefore, it can be seen that there are certain load speed and $d$ combinations that cause higher accelerations, while other combinations cause lower accelerations. Consequently, the dynamic response does not vary linearly: for a given load speed, higher $d$ values do not necessarily involve lower accelerations. Moreover, for a given $d$ value, higher load speeds do not necessarily involve higher accelerations. The response is therefore governed by resonance effects, in which for a given bridge geometry (i.e. $d$ value), certain load speeds tend to amplify accelerations ("amplification speeds"), while other load speeds tend to decrease them ("cancellation speeds"). Maximum

\section{Frequency Domain}

With the aim of studying the relative contribution of different modes to the dynamic response, the frequency domain record of the bridge was obtained by means of the fast Fourier transform. Since the minimum frequency obtained by this method depends on the inverse of the sample length, ${ }^{50}$ accelerograms of $30 \mathrm{~s}$ were considered, by including both the duration that the load was on the bridge and a free-vibration damping period.

The frequency domain response shows that the second vertical V2 is the mode that contributes most to the response. In those accelerations located in the "peaks" of the waves, the relative contribution of V2 is much higher than those of other modes, even though V2 is not the fundamental mode (see Fig. 7b). Nonetheless, the relative contribution of V2 decreases significantly for those speed- $d$ combinations located in the "valleys" of the waves. Hence, maximum accelerations are governed by the excitation of V2. In fact, the shape of the envelope of maximum accelerations along the deck is consistent with this finding, since maximum accelerations are located close to the sections where the contribution of V2 is maximum (see Fig. 6a). The additional contribution of other modes such as V3 may move the location of the maximum acceleration section slightly, such that it is not located exactly at a quarter of the span. The relative dominance of V2 in "peak" values decreases with $d$. This analysis also shows that the contribution of modes higher than $\mathrm{V} 4$ and $\mathrm{T} 4$ can be considered to be negligible in the context of the work presented here.

Finally, when comparing the maximum acceleration along the deck and the maximum acceleration at mid-span, it is observed that the difference between both values is larger for those speed- $d$ combinations located in the "amplified" accelerations (i.e. those located in the "peaks" of the waves) than the difference for combinations located in "cancelled" accelerations. In the first case, maximum accelerations can be $120 \%$ greater than those at mid-span, as opposed to a maximum of $40 \%$ in the second case. Therefore, the variation in the shape of the envelope of maximum accelerations along the deck (see Fig. 6a), confirms the strong influence of mode $\mathrm{V} 2$ on the response.

\section{Dynamic Response of UDCSB with Short Spans}

As in the case of the medium-span UDCSB, the dynamic response of a $40 \mathrm{~m}$ bridge was analysed to study the competitiveness of this bridge type for the short-span range. The span was subdivided into three equal subspans of $13.33 \mathrm{~m}$ each, and the cable staying system was provided with $4 \mathrm{~m}$ 
of eccentricity (i.e. $10 \%$ of the total span). The number of stay cables was also six, but each cable was formed by 19 strands of $150 \mathrm{~mm}^{2}$ each. The width of the deck remained equal, as well as the thickness of the reinforced concrete slab. However, the cross-section of the I-beams was modified, the new dimensions being (after performing exclusively static analyses to satisfy the corresponding ultimate limit states) a total height of $375 \mathrm{~mm}$, initially, with a web thickness of $7.5 \mathrm{~mm}$; a $400 \mathrm{~mm}$ wide and $12 \mathrm{~mm}$ thick upper flange; and a $640 \mathrm{~mm}$ wide and $20 \mathrm{~mm}$ thick lower flange. For this short span UDCSB, the height of the I-beams was modified in order to study the influence of this parameter on the response.

The analysis of modal frequencies shows the same tendencies as in medium-span UDCSBs, the frequencies increasing with $d$, but at a different rate depending on the mode. However, the absolute values of these frequen-
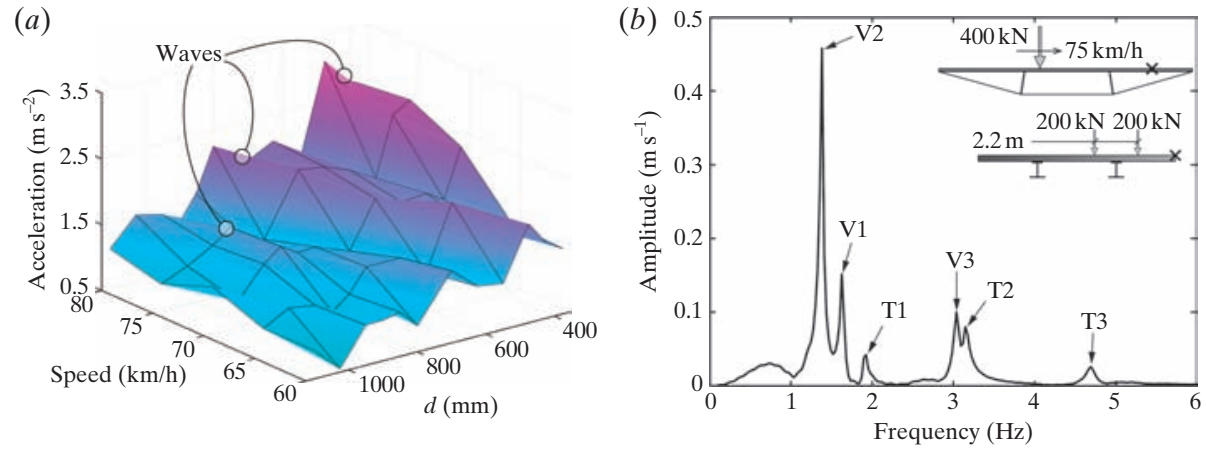

Fig. 8: Dynamic response of the $40 \mathrm{~m}$ span UDCSB: (a) maximum acceleration envelope for the eccentric load case; (b) frequency domain response of the accelerations at the edge of the middle section of the last subspan for a load speed of $75 \mathrm{~km} / \mathrm{h}$ and $d=375 \mathrm{~mm}$

son with the $80 \mathrm{~m}$ span (for the same I-beam depth $d$ to span ratio values). Eccentric loads also increase the maximum accelerations along the deck substantially. Nevertheless, the absolute acceleration values are considerably higher than for the $80 \mathrm{~m}$ span bridge. In fact, the peak acceleration for a 40 m span UDCSB (with $d=375 \mathrm{~mm}$ ) for the eccentric load case moving at 80 $\mathrm{km} / \mathrm{h}$ is $2.63 \mathrm{~m} / \mathrm{s}^{2}$, which is almost three times higher than that for a $80 \mathrm{~m}$ span bridge (with $d=750 \mathrm{~mm}$ ).

Figure $8 a$ shows the envelope of maximum accelerations for different $d$ and load speed values. The existence of waves with "peak" and "valley" values is also obvious. A frequency domain analysis shows the dominance of the V2 mode in those speed- $d$ combinations located in the "peaks", even when V2 is not the natural mode (see Fig. 8b). However, the relative contribution of mode V2 in comparison with the rest of the modes decreases in the "valleys".

\section{Design Criteria}

Codes and standards usually suggest a deflection control method to satisfy the comfort criteria of bridge users. This approach can be valid for some conventional bridges, but not for non-conventional bridge typologies. ${ }^{51}$ Figure $9 a$ shows a comparison of the verification of the SLS of vibrations through deflection-based and acceleration-based approaches for several UDCSB configurations in which the span and $d$ are varied. The frequent load combination is employed for the deflection control, ${ }^{47,52}$ together with the following limits: L/1000 exclusively for road bridges, and L/1200 for road bridges provided with footways. ${ }^{47}$ Moreover, the live load corresponding to the heaviest virtual lane defined by the Eurocode is applied with eccentricity to induce further torsional deformations, with the aim of comparing the results with those of the eccentric load case. Finally, the deflection limitations are calculated in two different ways: (a) by obtaining the ratio between the deflection at mid-span and the entire span of the bridge; and (b) by obtaining the ratio between the relative deflection of the central subspan (i.e. by substracting the deck-strut connection section deflection to the mid-span deflection ratio) and the length of the central subspan. The results clearly show a lack of affinity between the deflection- and acceleration-based methods, in which the former provides (a)

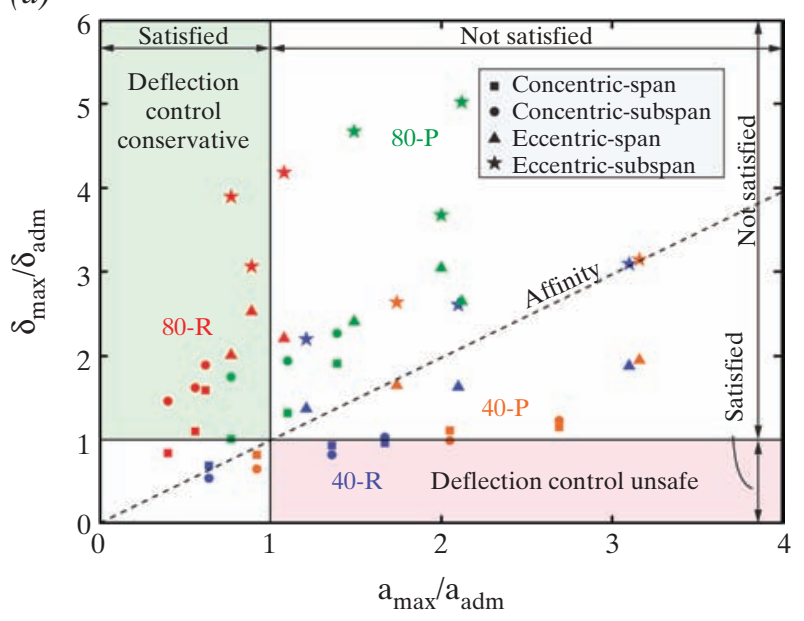

(b)

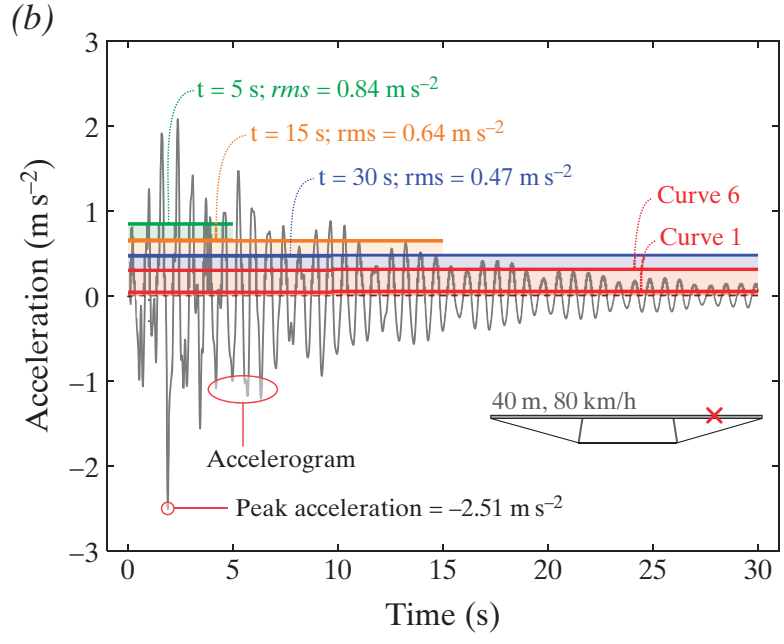

Fig. 9: (a) Comparison of the deflection- and acceleration-based methods to assess the SLS of vibrations (" 80 " refers to $80 \mathrm{~m}$ span UDCSBs; " 40 "to 40 m span UDCSBs; " $R$ " to exclusively road bridges; " $P$ " to road bridges with pedestrian footways; "concentric" to the concentric load case; "eccentric" to the eccentric load case; "span" to the deflection-based approach that considers the entire span length; and "subspan" to the deflection-based approach that only considers a subspan length). (b) Accelerogram of a $40 \mathrm{~m}$ span UDCSB at the mid-point of the last subspan $(d=375 \mathrm{~mm})$ with the load moving eccentrically at $80 \mathrm{~km} / \mathrm{h}$, with peak and rms values for different sample lengths (Curve 1 and Curve 6 represent the limits proposed in Ref. [53-54]) 
conservative results, leading to overdesign, in some bridge configurations, and unsafe results, leading to underdesign, in some others. The shorter the span, the less conservative the deflection-based approach is. Hence, accelerations on the deck have to be analysed if the SLS of vibrations needs to be studied, as deflections are not correlated with them.

Considering the peak acceleration of the accelerogram, it can be argued, does not provide a representative result of the dynamic response of the bridge, and a statistical tool that considers the accelerogram during a certain period of time can be used: the root mean square (rms). The rms is calculated as:

$r m s=\sqrt{\frac{1}{t_{2}-t_{1}} \int_{t_{1}}^{t_{2}}[f(x)]^{2} d x}$

where $f(x)$ is the continuous function under analysis (i.e. the accelerogram in this case), and $t_{1}$ and $t_{2}$ are the time intervals in which the rms is being calculated. Two different limits for $r m s$ acccelerations for bridges were proposed in Ref. [53-54]: Curve 1 for frequent events and Curve 6 for storm conditions. These limits are plotted in the accelerogram of Fig. $9 b$ together with the peak and rms values for different time lengths. The high influence of the length of the interval (i.e. $t_{2}-t_{1}$ ) in the rms value is observed, the rms acceleration being lower when increasing the interval length. In general, if the same time length is considered, the rms value has been viewed to be proportional to the peak acceleration for different UDCSB configurations. Hence, for the purpose of this paper, the peak accelerations were considered to assess the SLS of vibrations in UDCSBs because of the disparity between criteria and the lack of definition of the time length to be considered.

Owing to the subjectivity of the comfort phenomenon, codes and standards do not provide a commonly agreed criterion. When checking the comfort of pedestrians in road bridges provided with footways, the limits given by the Eurocode ${ }^{52}$ and the British Standards ${ }^{55}$ are considered: $0.7 \mathrm{~m} / \mathrm{s}^{2}$ and $0.5 \sqrt{f_{0}} \mathrm{~m} / \mathrm{s}^{2}$, respectively, where $\mathrm{f}_{0}$ is the natural frequency of the bridge in $\mathrm{Hz}$. On the other hand, when checking the comfort of vehicle occupants in road bridges (and because of the lack of a specific criterion), the limit given by the Eurocode for railway vehicle users is employed: $1 \mathrm{~m} / \mathrm{s}^{2}$ for a very
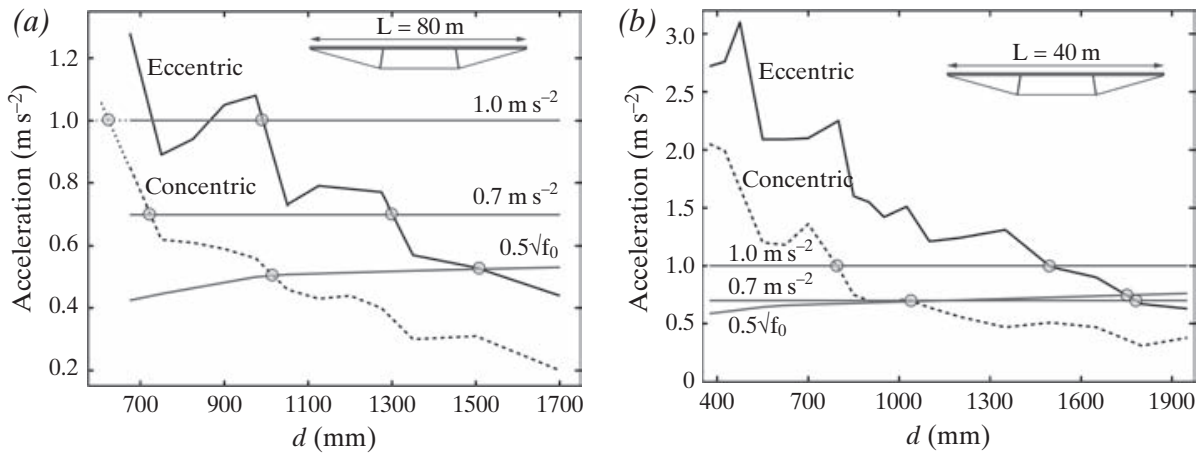

Fig. 10: Maximum accelerations registered on the deck for different $d$ values, and the limit provided by different codes for (a) an $80 \mathrm{~m}$ span UDCSB, and (b) a $40 \mathrm{~m}$ span UDCSB. The speed range considered is 60 to $80 \mathrm{~km} / \mathrm{h}$ with increments of $5 \mathrm{~km} / \mathrm{h}$

\begin{tabular}{|c|c|c|c|c|c|}
\hline & & \multicolumn{2}{|c|}{80 m } & \multicolumn{2}{c|}{40 m } \\
\hline & & Concentric & Eccentric & Concentric & Eccentric \\
\hline With pedestrians & EN 1990 & $1 / 78$ & $1 / 53$ & $1 / 30$ & $1 / 20$ \\
\hline & BS 5400 & $1 / 61$ & $1 / 44$ & $1 / 30$ & $1 / 20$ \\
\hline No pedestrians & EN 1990 & $1 / 86$ & $1 / 62$ & $1 / 36$ & $1 / 22$ \\
\hline
\end{tabular}

Table 3: Maximum slenderness of the deck (deck depth to span ratios) to satisfy the SLS of vibrations under different conditions ("With pedestrians" refers to road bridges with footways, while "No pedestrians" refers to road bridges with only vehicle users)

good comfort level. ${ }^{52}$ Maximum peak accelerations are compared with these limits in Fig. 10 for both 40 and $80 \mathrm{~m}$ spans. Maximum slenderness values for the deck are presented in Table 3, in which the deck depths are obtained by adding the concrete slab thickness to the $d$ value that satisfies the limits plotted in Fig. 10. The results show that the eccentricity of the vehicle penalises the maximum slenderness of the deck considerably.

In medium-span UDCSBs, slender decks can be adopted instead of conventional composite bridges without cable-staying systems. While the latter usually require depth to span ratios between $1 / 18$ and $1 / 20$, UDCSBs allow for slendernesses of $1 / 53$ for road bridges provided with footways and 1/62 for road bridges without footways. With these depthto-span ratios, UDCSBs present efficiencies $\xi$ of 74 and $78 \%$, respectively, under a uniformly distributed load along the entire span. However, for shorter spans, slender decks cannot be achieved because of the high accelerations registered under moving loads. If the eccentric load case is considered, depth to span ratios of $1 / 22$ and $1 / 20$ need to be provided for road bridges without footways and for those with footways, respectively. These slenderness values are similar to those conventionally used for bridges without cable-staying systems. As a result, relatively low efficiencies $\xi$ of
58 and $54 \%$ are obtained, respectively. Hence, UDCSBs are more appropriate for medium-span bridges than for short-span bridges from the dynamic viewpoint. In short-span UDCSBs, the employment of dampers would be necessary to satisfy the comfort criteria of bridge users without compromising the efficiency and deck slenderness.

\section{Conclusions}

UDCSBs are efficient bridge configurations that lead to lightweight construction. However, when employed for road bridges, the dynamic response under moving loads must be studied to assess the comfort of bridge users. Based on the analyses of the dynamics of UDCSBs and the results obtained, the main conclusions of this paper are as follows:

- The traditional deflection control method proposed by some codes is shown not to be valid to assess the SLS of vibrations of unconventional bridge typologies, and the direct measurement of accelerations becomes necessary.

- Higher speeds do not necessarily cause higher accelerations, and hence the whole vehicle speed range must be considered when assessing the SLS of vibrations of UDCSBs.

- Eccentric loads considerably increase maximum accelerations on the deck, so they should be taken into account in the design process. 
- The dynamic response of UDCSBs is governed by amplification speeds that amplify accelerations for certain load speed and geometry combinations.

- Maximum accelerations are registered in the lateral subspans rather than at mid-span, as the second vertical mode V2 is the principal mode that participates in the response.

- The SLS of vibrations governs the maximum slenderness of steelconcrete composite UDCSB decks when designed for road construction.

- For medium-span bridges with under-deck cable-staying systems, higher deck slenderness can be obtained as compared to conventional composite bridges without stays: double for road bridges with footways and three times for those without footways.

- Under-deck cable-staying systems are more appropriate for medium spans than for short spans because of the high accelerations registered on the deck in shorter spans.

\section{Acknowledgements}

The authors would like to express their gratitude to the Department of Education, Language Policy and Culture of the Basque Government, for the doctoral scholarship awarded to the first author. The authors are also thankful to Arturo Pérez Aguilar and Christian Balcázar Benítez (Mexpresa) for the photograph in Fig. 1a, and to Toshiyuki Nakagawa for the photograph in Fig. $1 b$.

\section{References}

[1] Gimsing NJ, Georgakis CT. Cable Supported Bridges - Concept and Design, 3rd edn. John Wiley \& Sons Ltd: Chichester, 2012.

[2] Ruiz-Teran AM, Aparicio AC. Two new types of bridges: under-deck cable-stayed bridges and combined cable-stayed bridges. The state of the art. Can. J. Civil Eng. 2007; 34(8): 1003-1015.

[3] Peters TF. Transitions in Engineering. Guillaume Henri Dufour and the Early 19th Century Cable Suspension Bridges. Birkhauser Verlag: Basel, Switzerland, 1987.

[4] Vogel RM. The engineering contributions of Wendell Bollman. In Contributions from the Museum of History and Technology. Smithsonian Institution: Washington DC. 1966; Paper 36, 77-104.

[5] Griggs FE. Thomas C. Clarke, bridge builder. ASCE J. Bridg. Eng. 2009; 14(4): 285-298.

[6] Griggs FE. Charles Macdonald. ASCE J. Bridg. Eng. 2010; 15(5): 565-580.

[7] Hines EM, Billington DP. Case study of bridge design competition. ASCE J. Bridg. Eng. 1998; 3(3): 93-102.

[8] Strasky J. Stress Ribbon and Cable-supported Pedestrian Bridges. ICE Publishing: London, UK, 2011.
[9] Institution of Civil Engineers. ICE Manual of Bridge Engineering. Thomas Telford: London, UK, 2008.

[10] Lin TY. Arch as architecture. Struct. Eng. Int. 1996; 6(2): 84-87.

[11] Muttoni A. Bridges with an innovative static system (Brücken mit einem innovativen statischen System). Schweiz. Ing. Archit. 1997; 26: 28-31 (in German).

[12] Leonhardt F. Brücken/Bridges. Deutsche Verlags-Anstalt: Stuttgart, Germany, 1994 (in German).

[13] Ruiz-Teran AM. Developments in underdeck and combined cable-stayed bridges. Proc. ICE Bridg. Eng. 2010; 163(2): 67-78.

[14] Schlaich J, Schober H. Highway overpass in Kirchheim [Steg über die Autobahn bei Kirchheim]. Beton- und Stahlbetonbau. 1994; 89(2): 40-44 (in German).

[15] Virlogeux M, Bouchon E, Lefevre J, Resplendino J, Crocherie A, Ageron C, Bourjot A, Clement M, Million P, Gudefin C, Valence M. A prestressed concrete slab supported from below: the Truc de la Fare Bridge. In Proceedings of the 12th FIP Congress, Washington DC, USA, 1994.

[16] Gonzalez A. Transverse axis of Catalonia. Section: Calldetenes-Sant Julià de VilatortaSant Sadurní d'Osormort [Eje transversal de Cataluña. Tramo: Calldetenes-Sant Julià de Vilatorta-Sant Sadurní d'Osormort]. Revista de Obras Públicas. 1997; 3364: 61-66 (in Spanish).

[17] Watanabe Y. Miho Museum bridge, Shigaraki, Japan. Struct. Eng. Int. 2002; 12(2): $245-247$.

[18] Forno JY, Cremer JM. Steel bridges and composite bridges designed in Greisch Office. In Proceedings of the 3rd International Conference on Composite Bridges. State-of-theart of their Technology and Analysis Methods, Madrid. CICCP, Madrid, 2001, 721-742 (in Spanish).

[19] Holgate A. The Art of Structural Engineering. The Work of Jörg Schlaich. Edition Axel Menges: Stuttgart, 1997.

[20] Troitsky MS, Zielinski ZA, Rabbani NF. Prestressed-steel continuous-span girders. J. Struct. Eng. 1989; 115(6): 1357-1370.

[21] Saitoh M, Okada A. The role of string in hybrid string structure. Eng. Struct. 1999; 21(8): 756-769.

[22] Xue W, Liu S. Studies on a large-span beam-string pipeline crossing. J. Struct. Eng. 2008; 134(10): 1657-1667.

[23] Andre A, Pacheco P, Adao da Fonseca A. Experimental study of a launching gantry reduced scale model strengthened with organic prestressing. Struct. Eng. Int. 2006; 16(1): 49-52.

[24] Egger H, Beck H. A new footbridge, Austria. Struct. Eng. Int. 1994; 4(4): 218-219.

[25] Adriaenssens S, De Voldere S, Ney L, Ochsendorf J, Strauwen I. Laurent Ney: Shaping Forces. A+ Editions (CIAUD-ICASD): Brussels, 2010.

[26] Kasuga A. Development of a new bridge construction method using suspension structures. Struct. Concrete 2011; 12(2): 65-75.
[27] Fernandez Troyano L, Iglesias Perez C. Bicentenario footbridge in Queretaro (Mexico). In Proceedings of the $V$ Congress of ACHE, Barcelona, Spain, 2011 (in Spanish).

[28] Saito D, Nakagawa T, Terada K. Introduction to a new steel bridge design method using sandwich slab technology. The Struct. Eng. 2012; 90(10): 51-58.

[29] Mutsuyoshi H, Hai ND, Kasuga A. Recent technology of prestressed concrete bridges in Japan. In Proceedings of the II IABSE-JSCE Conference on Advances in Bridge Engineering, Dhaka, Bangladesh, 2010.

[30] Flint \& Neill. Compiègne Bridge, France. Available from: http://www.flintneill.com.

[31] Baus U, Schlaich M. Footbridges: Construction, Design, History. Birkhäuser/Springer Verlag: Basel, 2008.

[32] Takeichi S, Kubo Y, Terada K, Saito D. Design of Awa Shirasagi Ohashi bridge. Struct. Eng. 2012; 90(8): 14-21.

[33] Ruiz-Teran AM, Aparicio AC. Parameters governing the response of under-deck cablestayed bridges. Can. J. Civ. Eng. 2007; 34(8): 1016-1024.

[34] Ruiz-Teran AM, Aparicio AC. Structural behaviour and design criteria of under-deck cable-stayed bridges and combined cable-stayed bridges. Part 1: Single span bridges. Can. J. Civ. Eng. 2008; 35(9): 938-950.

[35] Ruiz-Teran AM, Aparicio AC. Structural behaviour and design criteria of under-deck cable-stayed bridges and combined cable-stayed bridges. Part 2: Multi-span bridges. Can. J. Civ. Eng. 2008; 35(9): 951-962.

[36] Misiunaite I, Daniunas A, Juozapaitis A. Unconventional double-level structural system for under-deck cable-stayed bridges. J. Civ. Eng. Manage. 2012; 18(3): 436-443.

[37] Ruiz-Teran AM, Aparicio AC. Response of under-deck cable-stayed bridges to the accidental breakage of stay cables. Eng. Struct. 2009; 31(7): $1425-1434$.

[38] Camara A, Ruiz-Teran AM, Stafford PJ. Structural behaviour and design criteria of under-deck cable-stayed bridges subjected to seismic action. Earthquake Eng. Struct. Dyn. 2013; 42: 891-912.

[39] Meng X, Zhang C. Extradosed and intradosed cable-stayed bridges with continuous cables: conceptual consideration. ASCE J. Bridg. Eng. 2014; 19(1): 5-14.

[40] Oliveira Pedro JJ, Reis AJ. Non-linear analysis of composite steel-concrete cable-stayed bridges. Eng. Struct. 2010; 32(9): 2702-2716.

[41] Schlaich M. Erection of cable-stayed bridges having composite decks with precast concrete slabs. ASCE J. Bridg. Eng. 2001; 6(5): 333-339.

[42] Fryba L. A rough assessment of railway bridges for high-speed trains. Eng. Struct. 2001; 23(5): 548-556.

[43] Camara A, Nguyen K, Ruiz-Teran AM, Stafford PJ. Serviceability limit state of vibrations in under-deck cable-stayed bridges accounting for vehicle-structure interaction. Eng. Struct. 2014; 61: 61-72. 
[44] Kawaguchi M. Granite Pedestrian Bridge, Beppu, Japan. Struct. Eng. Int. 6(3): 148-149.

[45] Madrazo-Aguirre F, Ruiz-Teran AM, Wadee MA. Dynamic behaviour of under-deck cable-stayed bridges under the action of moving loads. In Proceedings of the 37th IABSE Symposium, Madrid, Spain, 2014.

[46] Abaqus. Version 6.10. Dassault Systèmes. Providence, MI, 2010.

[47] Ministry of Public Works, Spain. Instruction on the Loads to Be Considered in the Design of Road Bridges (IAP-11) [Instrucción sobre las acciones a considerar en el proyecto de puentes de carretera (IAP-11)]. Ministry of Public Works: Madrid, 2011 (in Spanish).
[48] O'Connor AJ, O'Brien EJ. Traffic load modelling and factors influencing the accuracy of predicted extremes. Can. J. Civ. Eng. 2005; 32: 270-278.

[49] Madrazo-Aguirre F, Ruiz-Teran AM, Wadee MA. Dynamic behaviour of steelconcrete composite under-deck cable-stayed bridges under the action of moving loads. Eng. Struct. (submitted).

[50] Santamarina JC, Fratta D. Discrete Signals and Inverse Problems: An Introduction for Engineers and Scientists. John Wiley \& Sons, Ltd: Chichester, 2005

[51] Ruiz-Teran AM, Aparicio AC. Verification criteria of the SLS of vibrations for road bridges with slender prestressed concrete decks. In
Proceedings of the 11th Annual International Fib Symposium, London, UK, 2009.

[52] European Committee for Standardization. EN 1990:2002. Eurocode 0, Basis of Structural Design. CEN: Brussels, 2002.

[53] Irwin AW. Human response to dynamic motion of structures. Struct. Eng. 1978; 9(56A): 237-244.

[54] Smith JW. Vibration of Structures Applications in Civil Engineering Design. Chapman and Hall: London, 1988.

[55] British Standards Institution (BSI). BS 5400-2:2006. Steel, Concrete and Composite Bridges - Part 2: Specification for Loads. BSI: London, UK, 2006.

\section{IABSE Conference Guangzhou 2016}

Bridges and Structures Sustainability Seeking Intelligent Solutions

May $8-11,2016$

Guangzhou, China

Call for Abstracts: May 31, 2015

- Structural Sustainability

- Intelligent Solutions

- High-Performance Materials

- Challenges in Major Projects

www.iabse.org/Guangzhou2016

\section{Organised by}

\section{The Chinese Group of IABSE}

and Guangzhou University Tongji University Hong Kong Zhuahai-Macau Bridge Authority 